\title{
PENGARUH GAYA KEPEMIMPINAN DAN BUDAYA ORGANISASI TERHADAP KEPUASAN KERJA PT. ARTOCHEM INDONESIA
}

\author{
Stella Anastasia Amanda dan Ronnie Resdianto Masman \\ Program Studi Manajemen Fakultas Ekonomi dan Bisnis \\ Universitas Tarumanagara, Jakarta \\ E-mail: stellaaasasela@gmail.com
}

\begin{abstract}
This study aimed to determine the effect of leadership style and organizational culture on the job satisfaction of PT. Artochem Indonesia in Jakarta. The sample in this study were employees who worked at PT. Artochem Indonesia. There are 50 respondents in this study. This study indicates that leadership style and organizational culture have a positive and significant influence on job satisfaction.
\end{abstract}

Keywords: Leadership Style, Organizational Culture, Job Satisfaction.

\begin{abstract}
Abstrak: Tujuan dari penelitian ini adalah untuk menentukan pengaruh gaya kepemimpinan dan budaya organisasi terhadap kepuasan kerja PT. Artochem Indonesia di Jakarta. Sampel pada penelitian ini adalah karyawan yang bekerja pada PT. Artochem Indonesia. Terdapat 50 responden dalam penelitian ini. Hasil penelitian ini yang menunjukkan bahwa gaya kepemimpinan dan budaya organisasi memiliki pengaruh positif dan signifikan terhadap kepuasan kerja.
\end{abstract}

Kata Kunci: Gaya Kepemimpinan, Budaya Organisasi, Kepuasan Kerja

\section{LATAR BELAKANG}

Di era globalisasi ini, tingkat persaingan antar perusahaan sangatlah tinggi, sehingga membuat perusahaan-perusahaan tersebut saling bersaing mendapatkan sumber daya manusia yang berkualitas dan kompeten. Salah satu aspek pendorong sumber daya manusia yang berkualitas dan kompeten adalah dengan adanya suatu kepemimpinan dan budaya organisasi, dimana keduanya memiliki hubungan yang sangat efektif. Setiap pemimpin tentunya memiliki gaya kepemimpinan yang berbeda, sehingga menghasilkan budaya organisasi yang berbeda pula. Maka tidak jarang suatu budaya organisasi dapat dikatakan mencerminkan kepemimpinan dalam organisasi itu sendiri. Sehingga baik kepemimpinan dan budaya organisasi sangat mempengaruhi kepuasan kerja pada setiap karyawan terhadap pekerjaannya, baik positif maupun negatif, yang akan menentukan suatu kualitas sumber daya manusia pada perusahaan. Kepuasan kerja karyawan menjadi perhatian dalam perusahaan ini, karena pimpinan perusahaan yang saat ini ingin mengetahui kepuasan kerja karyawan,gaya kepemimpinan dan budaya organisasi yang sudah terbentuk diperusahaan ini sebelum pimpinan yang saat ini mengambil alih dan perusahaan ini sebelumnya terdapat masalah dalam pengelolaan perusahaannya, maka pimpinan perusahaan yang saat ini meminta saya untuk meneliti perusahaannya saat ini untuk mengetahui kepuasan kerja karyawannya terhadap gaya kepemimpinan dan budaya organisasi di perusahaan ini.

PT. Artochem Indonesia didirikan di Jakarta Indonesia pada tahun 1995 dengan perwakilan yang berada di Surabaya, Palembang, Semarang dan Cirebon. PT. Artochem 
Indonesia merupakan perusahaan yang bergerak di bidang Importir, Trading, Stockist, Chemical Suppliers dan Fertilizer. PT. Artochem Indonesia salah satu perusahaan perdagangan utama dan juga pasar di Indonesia di bidang kedua bahan kimia umum dan kimia khusus. PT. Arthochem Indonesia sudah melayani banyak konsumen dengan jenis produk yang dimilikinya dan sesuai dengan kebutuhan konsumen dari berbagai daerah.

\section{KAJIAN TEORI}

Gaya Kepemimpinan merupakan suatu cara yang dimiliki seorang pimpinan yang menunjukkan suatu sikap yang menjadi ciri khas tertentu untuk mempengaruhi pegawainya dalam mencapai tujuan organisasi (Mulyadi,2015:150). Menurut Zainal et al., (2017:42) gaya kepemimpinan adalah sekumpulan ciri yang di gunakan pimpinan untuk mempengaruhi pegawainya agar sasaran organisasi tercapai atau dapat pula di katakan pola perilaku dan strategi yang diterapkan oleh seorang pemimpin. Menurut Busro (2018:226) gaya kepemimpinan adalah suatu cara bagaimana seorang pemimpin mampu memengaruhi para pengikut agar dengan suka rela mau melakukan berbagai tindakan bersama yang diperintahkan oleh pimpinan tanpa merasa bahwa dirinya ditekan dalam rangka mencapai tujuan organisasi.

Menurut Wardiah (2016:196) mengatakan budaya organisasi pada hakikatnya adalah nilai-nilai dasar organisasi yang akan berperan sebagai landasan bersikap, berperilaku dan bertindak bagi semua anggota organisasi. Budaya organisasi adalah cara orang berperilaku dalam organisasi dan ini merupakan satu set norma yang terdiri dari keyakinan, sikap, nilainilai dan pola perilaku dalam organisasi. Menurut Sutrisno (2015:2) mengatakan budaya organisasi dapat didefinisikan sebagai perangkat sistem nilai (value), keyakinan(beliefs), asumsi (assumptions), atau norma yang telah lama berlaku, disepakati dan diikuti oleh para anggota suatu organisasi sebagai pedoman perilaku dan pemecahan masalah-masalah organisasinya. Menurut Wahab dalam Tobari (2016:49) budaya organisasi merupakan suatu sistem nilai, kepercayaan dan kebiasaan dalam suatu organisasi yang saling berinteraksi dengan struktur sistem formalnya untuk menghasilkan norma-norma perilaku organisasi.

Menurut Siagian (Widodo, 2014) berpendapat bahwa kepuasan kerja merupakan suatu cara pandang seseorang, baik yang bersifat positif maupun bersifat negatif tentang pekerjaannya. Menurut Mila Badriyah (2015) juga mengemukakan bahwa kepuasan kerja adalah sikap atau perasaan karyawan terhadap aspek-aspek baik yang menyenangkan atau tidak menyenangkan mengenai pekerjaannya atau perilakuan kerja terhadap masingmasing. Menurut Bacotic (2013) menjelaskan kepuasan kerja kerap ditunjukkan oleh karyawan dengan cara mereka menyukai pekerjaan tersebut serta tingkat kesenangannya saat mengerjakan pekerjaan, umumnya dapat dikatakan bahwa kepuasan kerja adalah kenyamanan serta hubungan yang positif antar sesama karyawan. 
Kerangka pemikiran dalam penelitian ini sebagai berikut:

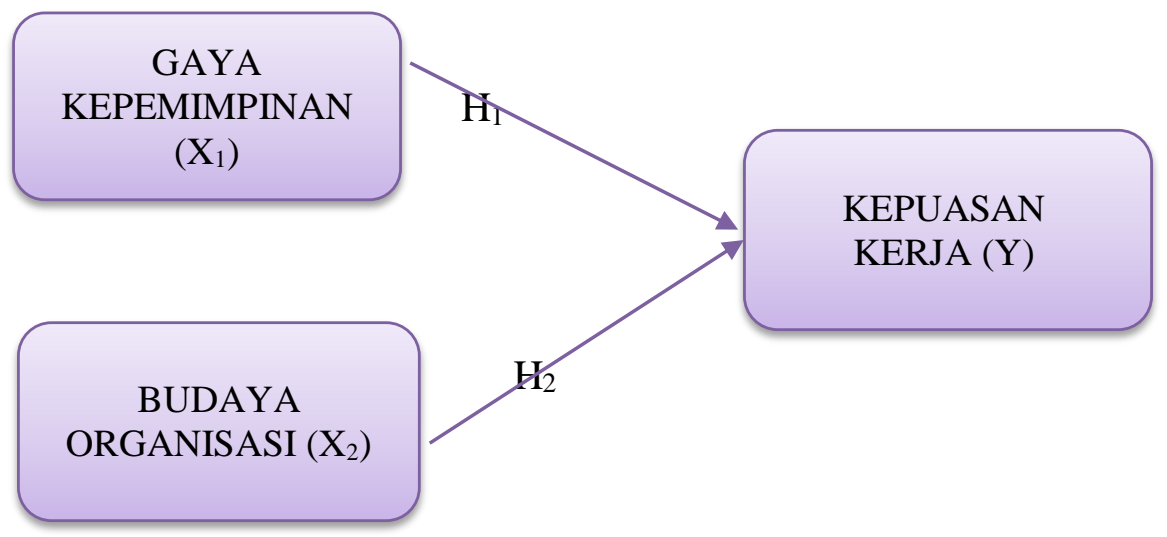

Gambar 1. Model Penelitian

Hipotesis:

Berdasarkan kajian teori dan kerangka pemikiran, maka hipotesis yang di bentuk adalah :

H1 : gaya kepemimpinan memiliki pengaruh terhadap kepuasan kerja karyawan pada PT. Artochem Indonesia di Jakarta

$\mathrm{H} 2$ : budaya organisasi memiliki pengaruh terhadap kepuasan kerja karyawan pada PT. Artochem Indonesia di Jakarta.

\section{METODOLOGI}

Desain penelitian adalah rencana (desain) yang dibuat seorang peneliti dalam rangka membuktikan hipotesis yang sudah dikemukakan sebelumnya. Menurut Sekaran dan Bougie (2013), mengatakan bahwa desain penelitian adalah suatu rencana penelitian secara ilmiah dalam rangka menjawab pertanyaan yang terdapat dalam identifikasi masalah. Penelitian ini akan menggunakan penelitian kuantitatif kausal, yang menurut Sekaran \& Bougie (2016 : 14) penelitian kausal adalah suatu penelitian yang dilakukan untuk melihat hubungan sebab-akibat suatu variabel. Dalam penelitian ini populasi dan sampel yang diambil adalah seluruh karyawan pada PT. Artochem Indonesia di Jakarta yang memiliki karyawan sebanyak 50 karyawan. Teknik pengumpulan data dalam penelitian ini menggunakan kuesioner. Aplikasi yang digunakan peneliti dalam penelitian ini adalah SmartPLS versi 3. Uji statistik yang digunakan dalam SmartPLS versi 3 adalah sebagai berikut:

Uji Validitas, menggunakan convergent validity yaitu suatu indikator dikatakan valid apabila nilai outer loading di atas 0.5 (Ghozali, 2014). Convergent validity juga menilai AVE (Average Variance Extraced) apabila diatas 0.5 maka variabel dikatakan valid. Menurut Sugiyono (2013, h. 202) validitas merupakan derajat ketetapan antara data yang ada pada objek penelitian dengan daya yang dilaporkan oleh penelitian.

Uji Reliabilitas, menggunakan metode Alpha-Cronbach. Tingkat reabilitasnya diukur berdasarkan skala alpha 0 sampai dengan 1. Kuesioner bersifat reliable apabila memiliki nilai alpha lebih besar dari 0.7. Menurut Sekaran dan Bougie (2016, p. 223), reliabilitas adalah keandalan untuk membuktikan alat ukur sesuai dengan stabilitas dan konsistensi. Selanjutnya, untuk hasil analisis data dapat dilakukan pengujian sebagai berikut: 
1. Uji Koefisien Determinan (Uji R) yaitu pengujian yang dilakukan apabila R2 semakin besar atau mendekati 1, maka dapat disimpulkan model tersebut semakin tepat. Koefisien determinasi pada regresi linear biasa disebut sebagai seberapa besar kemampuan semua variabel bebas dalam menjelaskan varians dari variabel terikat.

2. Uji Hipotesis yaitu Variabel independen menunjukkan tingkat signifikan apabila nilai $\mathrm{t}$ value $\geq 1,96$ pada tingkat alpha $5 \%$. Uji hipotesis juga terkadang disebut dengan konfirmasi analisis data.

3. Uji Goodness of Fit adalah pengujian hipotesis kompatibilitas (goodness of fit) merupakan pengujian hipotesis untuk menentukan apakah suatu himpunan frekuensi yang diharapkan sama dengan frekuensi yang diperoleh dari suatu distribusi, seperti distribusi binomial, normal, atau dari perbandingan lain. Pengujian ini digunakan untuk mengvalidasi performa gabungan antara outer model dan inner model yang memiliki range nilai antara $0-1$ dengan interpretasi 0-0,25 (Gof Kecil), 0,25-0,36 (Gof Moderat), dan >36 (Gof Besar).

\section{Hasil Uji Statistik}

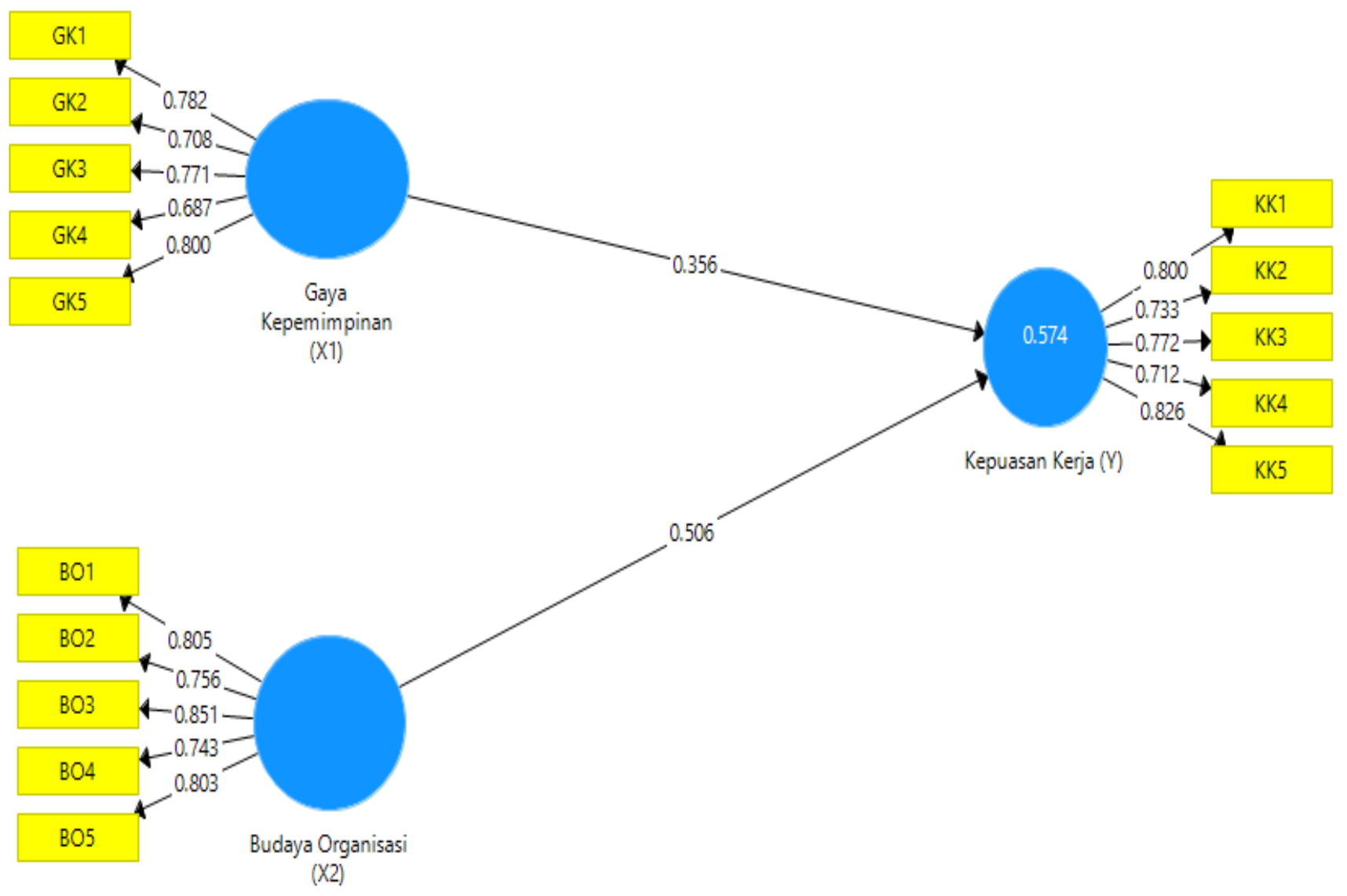

Gambar 2. Hasil Outer loading SmartPLS 


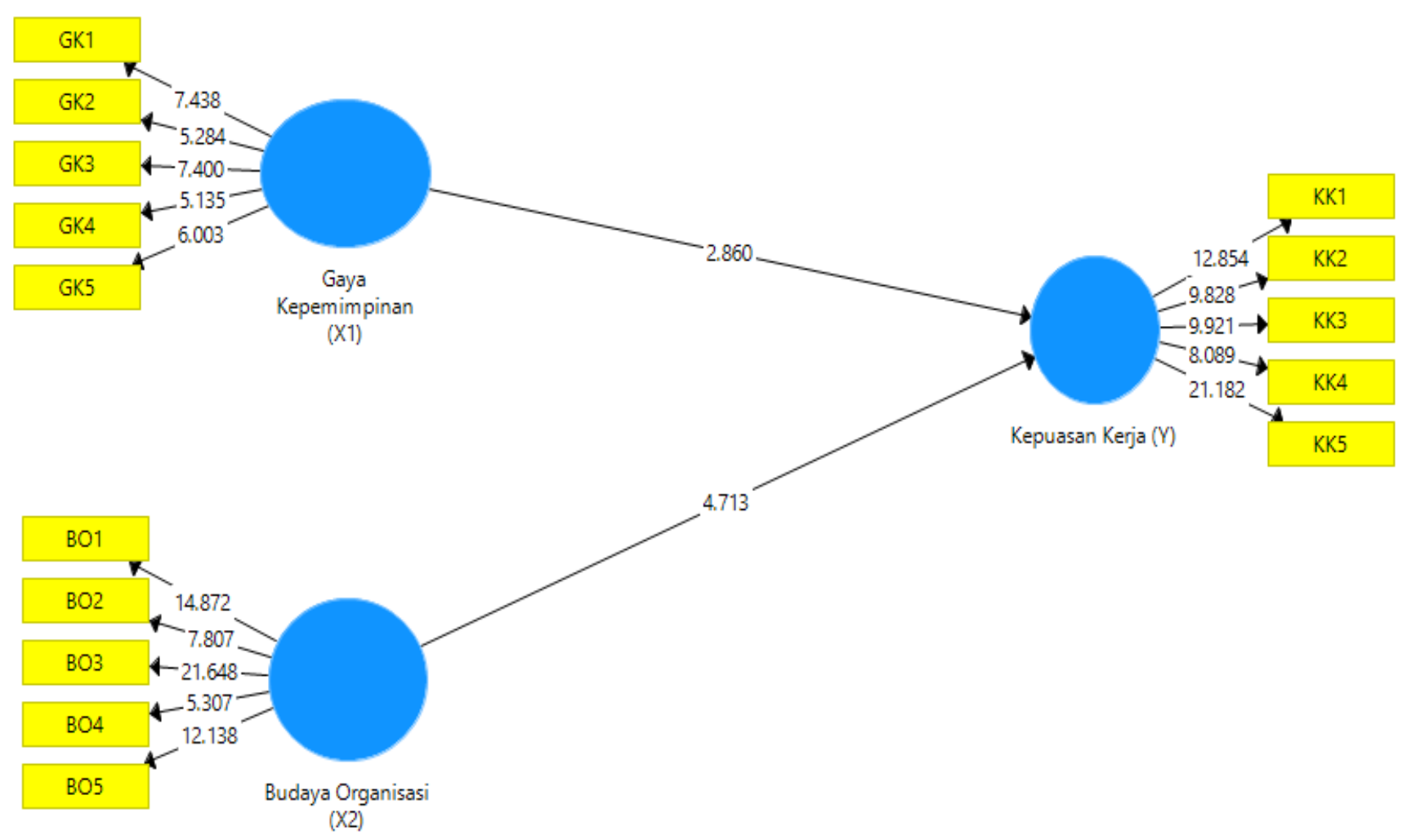

Gambar 3. Hasil Uji Bootsrapping

Dari 50 responden, 27 orang berjenis kelamin perempuan dan 23 orang berjenis kelamin laki-laki. Sebagian besar responden berusia 20 tahun sampai 25 tahun (35 orang, $70 \%$ ) dan sisanya berusia 26 tahun sampai 30 tahun (11 orang, 22\%), dan yang lebih dari 40 tahun (4 orang, 8\%). Pendidikan terakhir sebagian responden adalah S1 (31 orang, $62 \%$ ), S2 (8 orang, 16\%) dan sisanya SMA/SMK (11 orang, 22\%). Durasi lama bekerja sebagian besar responden adalah kurang dari 1 sampai 5 tahun (23 orang, 46\%) dan sisanya 1 tahun sampai 3 tahun (16 orang, 32\%), dan antara 4 tahun sampai 6 tahun (11 orang, 22\%).

Penulis akan membahas tentang hasil pengolahan data dengan software SmartPLS berdasarkan gambar di atas:

\section{Uji Validitas}

\begin{tabular}{|c|c|}
\hline Gaya Kepemimpinan (X1) & 0.628 \\
\hline Budaya Organisasi(X2) & 0.564 \\
\hline Kepuasan Kerja (Y) & 0.593 \\
\hline
\end{tabular}

Nilai $A V E$ dari setiap variabel adalah lebih besar dari 0.5 sehingga dapat ditarik kesimpulan bahwa semua variabel telah memiliki hasil uji validitas yang baik.

\section{Uji Reliabilitas}

\begin{tabular}{|l|l|}
\hline & Cronbach'Alpha \\
\hline
\end{tabular}




\begin{tabular}{|c|c|}
\hline Gaya Kepemimpinan (X1) & 0.852 \\
\hline Budaya Organisasi (X2) & 0.805 \\
\hline Kepuasan Kerja (Y) & 0.828 \\
\hline
\end{tabular}

Nilai cronbach-alpha untuk tiap variabel adalah lebih besar dari 0,7 sehingga dapat di simpulkan bahwa pernyataan untuk setiap variabel adalah reliable.

\section{Uji Koefisien Determinan $\left(\mathbf{R}^{2}\right)$}

\begin{tabular}{|c|c|c|}
\hline & R Square & $\begin{array}{c}\text { R Square } \\
\text { Adjusted }\end{array}$ \\
\hline Kepuasan Kerja (Y) & 0.574 & 0.556 \\
\hline
\end{tabular}

Berdasarkan hasil Adjusted $R$ Square $\left(\mathrm{R}^{2}\right)$ pada tabel diatas adalah 0.556 , artinya di mana proporsi gaya kepemimpinan dan budaya organisasi sebesar $55.6 \%$ dan sisanya sebesar $44.4 \%$ dijelaskan pada variabel kepuasan kerja. Sedangkan hubungan kepuasan kerja terhadap gaya kepemimpinan dan budaya organisasi berdasarkan hasil nilai $\mathrm{R}$ Square adalah 0.574 yaitu positive dan signifikan bahwa ada hubungan kepuasan kerja terhadap gaya kepemimpinan dan budaya organisasi.

\section{Uji Hipotesis}

\begin{tabular}{|c|c|c|c|c|c|}
\hline & $\begin{array}{c}\text { Original } \\
\text { Sample } \\
(\mathbf{O})\end{array}$ & $\begin{array}{c}\text { Sample } \\
\text { Mean (M) }\end{array}$ & $\begin{array}{c}\text { Standard } \\
\text { Deviation }\end{array}$ & T Statistics & P Values \\
\hline $\begin{array}{c}\text { Gaya Kepem-impinan } \\
\text { (X1) -> Kepuasan } \\
\text { Kerja (Y) }\end{array}$ & 0.356 & 0.352 & 0.124 & 2.860 & 0.004 \\
\hline $\begin{array}{c}\text { Budaya Organ-isasi } \\
\text { (X2) -> Kepuasan } \\
\text { Kerja }\end{array}$ & 0.506 & 0.524 & 0.107 & 4.713 & 0.000 \\
\hline
\end{tabular}

a Dari hasil pengujian variabel gaya kepemimpinan terhadap kepuasan kerja karyawan memiliki koefisien jalur 0.356 dan T-Value sebesar 2.860 dimana T-Value lebih besar dari 1.96. Oleh karena itu dapat disimpulkan gaya kepemimpinan memiliki pengaruh signifikan terhadap kepuasan kerja karyawan PT. Artochem Indonesia.

b Dari hasil pengujian variabel budaya organisasi terhadap kepuasan kerja karyawan memiliki koefisien jalur 0.506 dan T-Value sebesar 4.713 dimana T-Value lebih besar dari 1.96. Oleh karena itu dapat disimpulkan budaya organisasi 
memiliki pengaruh signifikan terhadap kepuasan kerja karyawan PT. Artochem Indonesia.

\section{Uji Goodness of Fit}

\begin{tabular}{|c|c|}
\hline & Saturated Model \\
\hline NFI & 0.634 \\
\hline
\end{tabular}

Nilai ini berkisar dari $0-1$, nilai NFI yang mendekati 1 menunjukan bahwa model yang diuji memiliki ketepatan yang baik.

\section{KESIMPULAN}

Berdasarkan hasil penelitian yang dilakukan di PT. Artochem Indonesia yang dilakukan oleh peneliti, maka dapat disimpulkan sebagai berikut:

a. Terdapat pengaruh yang positif variabel gaya kepemimpinan terhadap kepuasan kerja karyawan PT. Artochem Indonesia.

b. Terdapat pengaruh yang positif variabel budaya organisasi terhadap kepuasan kerja karyawan PT. Artochem Indonesia.

\section{PENUTUP}

Berdasarkan dari hasil penelitian yang telah dilakukan, peneliti akan memberikan beberapa saran atau masukan yang sekiranya dapat digunakan atau bermanfaat bagi perusahaan maupun kepada penelitian selanjutnya, sebagai berikut:

\section{a. Untuk PT. Artochem Indonesia}

Sebaiknya perusahaan tetap terus mempertahankan kepuasan kerja karyawannya supaya bisa mencapai tujuan serta target yang sudah pernah di terapkan oleh perusahaan. Kepuasan kerja dapat dipertahankan oleh perusahaan dengan cara memberikan gaya kepemimpinan yang baik serta memberikan kepemimpinan yang positif kepada para karyawan supaya mereka terus bisa semangat dalam bekerja di perusahaan tersebut. Perusahaan juga diharapkan bisa tetap mempertahankan budaya organisasi perusahaan untuk menciptakan loyalitas antar karyawan dan pemimpin untuk dapat menciptakan lingkungan kerja yang kondusif berjalan dengan baik dalam jangka waktu yang lama. Oleh karna itu, manajemen perusahaan wajib dapat mempertahankan gaya kepemipinan dan budaya organisasi yang baik untuk karyawan supaya mereka bisa bekerja dengan baik dan juga akan terus berusaha buat tingkatkan kinerja dan kepuasan karyawan demi kemajuan perus-ahaan kedepannya.

b. Untuk peneliti selanjutnya

Diharapkan untuk menambah jumlah sampel dan variabel penelitian. Karena semakin banyak sampel dan variabel yang ada maka data yang dihasilkan akan lebih bervariasi, serta menyiapkan indikator yang tepat sesuai dengan kondisi perusahaan agar mendapatkan hasil yang diinginkan. 


\section{DAFTAR PUSTAKA}

Abdurrahmat, Fathoni. 2006. Manajemen Sumber Daya Manusia. Bandung: Rineka Cipta

Alex S. Nitisemito, (1992), Manajemen dan Sumber Daya Manusia, BPFE UGM,. Yogyakarta.

Ali, K., \& Agustian, D. W. (2019). Pengaruh Budaya Organisasi Dan Gaya Kepemimpinanterhadap Kepuasan Kerja (Studi Di Rumah Sakit Muhammadiyah Metro). Jurnal Manajemen Magister Darmajaya, 4(02), 186196.

Al-Sada, M., Al-Esmael, B., \& Faisal, M. N. (2017). Influence of organizational culture and leadership style on employee satisfaction, commitment and motivation in the educational sector in Qatar. EuroMed Journal of Business.

Bangun, Wilson. 2012. Manajemen Sumber Daya Manusia. Jakarta: Erlangga.

Febbyani, A., \& Masman, R. R. (2019). Pengaruh Gaya Kepemimpinan, Kompensasi, Dan Lingkungan Kerja Terhadap Kinerja Karyawan Pada PT. Apatel. Jurnal Manajerial Dan Kewirausahaan, 1(4), 725-735.

Ghozali, Imam. 2014. Structural Equation Modeling, Metode Alternatif dengan Partial Least Square (PLS). Edisi 4. Semarang: Badan Penerbit Universitas Diponegoro.

Chandra, J. C., \& Masman, R. R. (2020). Pengaruh Kompensasi dan Lingkungan Kerja terhadap Kinerja Karyawan Pada PT Klasik Distribusi Indonesia. Jurnal Manajerial Dan Kewirausahaan, 2(4), 977-984.

Malayu S.P. Hasibuan. 2016, Manajemen Sumber Daya Manusia, edisi revisi, Cetakan Kesembilan belas, PT Bumi Aksara, Jakarta.

Margono, S. (2005). Metode Penelitian Pendidikan, Jakarta: Rineka Cipta, 1997. Subana, Drs, Statistik Pendidikan, Bandung: Pustaka Setia.

Pawirosumarto, S., Sarjana, P. K., \& Gunawan, R. (2017). The effect of work environment, leadership style, and organizational culture towards job satisfaction and its implication towards employee performance in Parador Hotels and Resorts, Indonesia. International Journal of Law and Management.

Robbins P. Stephen and Marry Coulter. 2017. Manajemen. Erlangga. Jakarta.

Robbins P. Stephen, dan Judge. 2011. Perilaku Organisasi, Salemba Empat, Jakarta.

Saputra, I. G. A. E., \& Adnyani, I. G. A. D. (2017). Pengaruh Pengaruh Gaya Kepemimpinan dan Budaya Organisasi terhadap Kepuasan Kerja Karyawan. EJurnal Manajemen, 6(12), 6592-6619.

Sekaran, U., \& Bougie, R. (2016). Research Methods for Business: A Skill Building Approach Seventh Edition. Chichester, West Sussex, United Kingdom: Wiley.

Sekaran, U., and R. Bougie. (2013). Research Method For Business. Chennai, India: Johan Wiley \& Sons Ltd.

Sekaran, U., and R. Bougie. (2017). Metode Penelitian Bisnis. Edisi 6 \& Buku 2. Salemba Jakarta.

Stephen P. Robbins “Teori Organisasi. Struktur, Desain \& Aplikasi Edisi 3. Penerbit Arcan.

Sulaksono, Ki Hari. Kepemimpinan dan Budaya Organisasi. Edisi 1, Cetakan ke 1. Yogyakarta: Deepublish, Mei 2016.

Tambunan, Toman S. 2015. "Pemimpin dan Kepemimpinan“. Yogyakarta: Graha 
Ilmu.

Wun, M. O., \& Masman, R. R. (2020). Pengaruh Lingkungan Kerja, Penilaian Kinerja, Gaya Kepemimpinan Terhadap Kepuasan Kerja Karyawan FEB Universitas Tarumanagara Di Jakarta. Jurnal Manajerial Dan Kewirausahaan, 2(1), 90-101.

Waliningsuci, T., Al Musadieq, M., \& Hamid, D. (2019). Pengaruh Budaya Organisasi Dan Gaya Kepemimpinan Terhadap Kepuasan Kerja Dan Kinerja Karyawan. PROFIT: JURNAL ADMINISTRASI BISNIS, 11(1), 1-11.

Yukl, Gary. 2015, Leadership in Organizations, Seventh Edition, PT. Indeks, Jakarta. 